\title{
Do vehicle efficiency improvements lead to energy savings? The Rebound Effect in Great Britain
}

\author{
Matteo Craglia ${ }^{1, *}$, Jonathan Cullen ${ }^{1}$ \\ University of Cambridge, Trumpington Street, Cambridge, CB2 1PZ, UK
}

\begin{abstract}
Fuel efficiency improvements in vehicles reduce the cost of travel, which could stimulate drivers to travel further limiting energy savings. Estimates of this effect, known as the rebound effect, have varied widely, partly due to data constraints and a reliance upon highly aggregated government statistics. This paper instead uses a dataset of over 275 million vehicle roadworthiness tests. The high level of detail in our dataset can reveal, for the first time, how the response to changes in travel costs may differ across types of vehicles and socio-economic areas in Great Britain.

We find that the rebound effect in Great Britain is just 4.6\%, meaning efficiency improvements are unlikely to stimulate increased mileage in the short-run. We find that larger, less fuel efficient vehicles are more responsive to fuel price changes than smaller vehicles and that drivers in urban areas are more responsive to fuel price changes than drivers in rural areas. Our findings shed light on the effects that policies such as fuel taxation and fuel economy standards may have on vehicle mileage. This has implications for both $\mathrm{CO}_{2}$ emissions savings and social equity.
\end{abstract}

\section{Introduction}

Improving the energy efficiency of passenger cars is considered an important measure to reduce energy demand and combat the effects of climate change. Given the unmet potential for efficiency improvements in vehicles [1, regions ranging from the European Union (EU) to the USA have implemented fuel economy and $\mathrm{CO}_{2}$ emissions standards to stimulate manufacturers to produce more efficient cars. Equally, several national governments have adopted fuel taxes to shift consumers to more efficient travel alternatives. The energy saving potential of these policies depends upon how drivers react to vehicle efficiency improvements and fuel price changes.

Improvements in the energy efficiency of vehicles, and the resulting fuel cost savings, may stimulate drivers to travel more. This phenomenon is known as the rebound effect, and if large, could offset potential energy savings from efficiency improvements. Quantifying the magnitude of the rebound effect reliably is important to estimate realistic emissions savings and societal benefits from energy efficiency policies such as fuel economy standards.

However, estimates of the rebound effect in passenger transport have varied widely due to different methods and types of data 2, 3]. Part of this uncertainty may be due to studies estimating rebound effects using travel data at a high level of aggregation (e.g. at the national level) [2]. This risks omitting important underlying variables and being dependent upon historical data from periods with dif-

\footnotetext{
* Corresponding Author

Email address: mamc4@cam.ac.uk (Matteo Craglia)
}

ferent characteristics of transport demand. Highly aggregated data also masks social and geographical differences in how drivers react to efficiency improvements. Understanding these differences is important in policy appraisal for both quantifying rebound effects and addressing social equity concerns.

To overcome these limitations, this paper uses a novel and more detailed dataset of vehicle roadworthiness tests to investigate the rebound effect in Great Britain. Using odometer readings for over 50 million unique vehicles, tracked over time between 2006 and 2017, we further investigate how rebound effects may differ geographically and between different types of vehicles.

\section{Literature Review}

\subsection{The rebound effect and the effects of fuel price}

Energy efficiency improvements can have the effect of reducing the costs of an energy service $S$. For an energy service like passenger transport, efficiency improvements in vehicles can reduce the price of travel $\left(P_{S}\right)$ and thereby stimulate travel demand. The cost of driving is dependent upon the price of fuel, $P_{E}$ (with units price/energy) and the efficiency of the vehicle $\varepsilon$ (with units energy/distance traveled) according to:

$$
P_{S}=P_{E} / \varepsilon
$$

The rebound effect in passenger transport is the effect that a change in energy efficiency $(\varepsilon)$ has on travel demand (typically expressed as vehicle miles traveled, VMT). This is 
generally expressed as the elasticity $\eta_{\varepsilon}(S)$ of travel demand with respect to efficiency:

$$
\frac{\partial S}{S}=\eta_{\varepsilon}(S) \frac{\partial \varepsilon}{\varepsilon}
$$

This elasticity shows how much a percentage change in energy efficiency $\varepsilon$ changes travel demand $S$. With an elasticity of $\eta_{\varepsilon}(S)=0.5$, a $10 \%$ increase in energy efficiency would lead to a $0.5 \times 0.1=5 \%$ increase in mileage. This would therefore offset $50 \%$ of the potential energy savings. However, using $\eta_{\varepsilon}(S)$ as a measure of the rebound effect is often problematic due to the possibility that energy efficiency is not an exogenous variable; independent of energy prices, travel demand $S$ and other confounding variables [2. If consumers buy vehicles with better energy efficiency in times of high oil price, or because they expect to drive a greater annual distance (perhaps due to a change of employment or living circumstances), then estimates of efficiency elasticities could be biased. Empirical constraints mean it is often not possible to control for these factors sufficiently to calculate the impact of an exogenous efficiency improvement. For these reasons, fuel price elasticities $\eta_{P_{E}}(S)$ are often used as a measure of the rebound effect:

$$
\frac{\partial S}{S}=\eta_{P_{E}}(S) \frac{\partial P_{E}}{P_{E}}
$$

Empirically, calculating $\eta_{P_{E}}(S)$ has the advantage that the price of fuel can be considered exogenous in a way that efficiency $\varepsilon$ rarely can. Another advantage is fuel prices typically have greater temporal variation as explanatory variables than efficiencies. The elasticity $\eta_{P_{E}}(S)$ can be assumed to be equal in magnitude and opposite in sign to $\eta_{\varepsilon}(S)$ under certain assumptions:

1. drivers react to changes in travel costs $\left(P_{S}\right)$ from fuel price changes $\left(P_{E}\right)$ and from efficiency improvements $(\varepsilon)$ in the same way,

2. drivers are limited in shifting travel to other types of transport [4,

3. fuel prices $P_{E}$ and efficiency $\varepsilon$ are exogenous and independent of travel demand or other variables.

These assumptions can be used to gauge an estimate of the rebound effect $\eta_{\varepsilon}(S)$, by estimating $-\eta_{P_{E}}(S)$. If efficiency improvements are affected by fuel prices, $\varepsilon=f\left(P_{E}\right)$, as shown for example by [5, 6], then the following equation can be derived (derivation in SI):

$$
\eta_{P_{S}}(S)=\eta_{P_{E}}(S) \times \frac{1}{1-\eta_{P_{E}}(\varepsilon)}
$$

where $\eta_{P_{E}}(\varepsilon)$ is the elasticity of fuel prices on efficiency and is expected to be greater than zero if higher fuel prices stimulate higher efficiency. This means estimates of $\eta_{P_{E}}(S)$ are likely to underestimate the rebound effect $[7]$ since:

$$
\left|\eta_{P_{E}}(S)\right| \leq\left|\eta_{P_{S}}(S)\right|
$$

Literature estimates of $\eta_{P_{E}}(\varepsilon)$ lie between 0.005-0.04 in the short-run, rising to $0.1-0.2$ in the long-run [5, 6, 8, 9]. This means estimates of $\eta_{P_{E}}(S)$ are likely to underestimate the rebound effect by just $0.5-4 \%$ in the short-run and $11-25 \%$ in the long run meaning $\eta_{P_{E}}(\varepsilon)$ is a close approximation to the rebound effect in the short-run. In this paper, the rebound effect is estimated as $-\eta_{P_{E}}(S)$.

\subsection{Empirical estimates of the rebound effect}

Sorrell et al. 2 present a comprehensive review of studies investigating the rebound effect building upon earlier reviews [10, 11. Table 1 presents a selection of more recent studies quantifying the rebound effect in passenger vehicle transport by means of $\eta_{P_{E}}(S)$. Estimates of rebound effects vary widely in the academic literature due to differences both in the type of data, geographic region, time period and estimation technique. Data can broadly be classified into aggregate and micro-level, based on the cross-sectional detail of the data. In turn, microlevel panel data can be further split into survey data and vehicle testing data with odometer readings. The former often benefits from data on socio-economic characteristics about drivers. The latter often lacks this data but benefits from much larger sample sizes.

To date, the majority of rebound studies have made use of aggregate national statistics due to the availability of data [2. However, using aggregate data to estimate the effects of efficiency improvements or fuel prices on mileage presents three main limitations.

Firstly, using aggregate data often requires long time series in order to have a sufficient number of sample points to yield statistically significant results. Several authors [8, 19, 21] have shown that the rebound effect may decrease as average incomes rise over time and drivers reach 'saturation' in demand for travel. Hughes et al. 21] for example find that $\eta_{P_{E}}(S)$ in the USA decreased from between -0.21 and -0.34 in 1975-1980 to between -0.034 and -0.077 in the 2001-2006 period. The use of long time series data may therefore cover time periods in the past which are no longer appropriate for policy-making on future travel demand.

Secondly, it is difficult to account for the many other underlying geographical and social trends affecting travel while using aggregate data. These can be controlled to a greater extent using micro-level panel data such as household surveys and vehicle odometer readings.

Finally, micro-data can help to reveal heterogeneity as certain drivers may be more susceptible to fuel price or fuel efficiency changes, than others, based on their ability to pay or their ability to choose alternative modes of transport.

This social and geographical heterogeneity is useful for comparing the results of studies in different countries. For example, Gillingham et al. [18] used odometer data and found fuel price elasticities were lower in the USA than in Denmark. The authors suggest this difference can be explained by the extremities of the mileage distribution 


\begin{tabular}{|c|c|c|c|c|c|}
\hline Authors & Years & Country/Region & Data Type & Observations & $\eta_{P_{E}}(S)$ \\
\hline Stapleton et al. $[12]$ & $1970-2011$ & Great Britain & Aggregate & 41 & -0.152 \\
\hline Frondel \& Vance 13 & 1997-2009 & Germany & HH Survey & 4,097 & -0.574 \\
\hline Knittel \& Sandler 14 & $1996-2010$ & California,USA & Odometer & $3,640,433$ & $-0.117,-0.265$ \\
\hline Gillingham et al.[15] & 2001-2009 & California,USA & Odometer & $5,038,554$ & -0.22 \\
\hline Langer et al. 16 & 2009-2013 & Arizona,USA & Odometer & 228,910 & -0.15 \\
\hline Gillingham et al. 17] & $2000-2010$ & Pennsylvania,USA & Odometer & $30,621,721$ & -0.10 \\
\hline Gillingham & 1998-2011 & Denmark & $\begin{array}{l}\text { Odometer \& } \\
\text { HH Survey }\end{array}$ & $5,855,446$ & -0.3 \\
\hline
\end{tabular}

Table 1: Selected recent studies quantifying fuel price elasticities in different countries split by data type: aggregate national time series data, household $(\mathrm{HH})$ survey panel data, vehicle testing odometer panel data.

(drivers with particularly high or low mileage) being more sensitive to fuel price in Europe than in the USA, perhaps due to greater public transport provision.

Understanding the spectrum of responses to fuel prices and efficiency improvements is important to factor into policy design. For example both Knittel \& Sandler 14 and Langer et al. [16] use odometer level data to show owners of higher fuel consumption vehicles are more sensitive to fuel price changes in California and Arizona in the USA respectively. This suggests fuel taxes could affect the mileage of larger vehicles more than small vehicles, though there is yet to be a similar study in a European context, where fuel taxes are already high.

To date there have been limited studies estimating the rebound effect and fuel price elasticities in Great Britain. Stapleton et al. [12] use national aggregate data covering 1970-2011 and estimate rebound effects in the order of 15\%. Dargay et al. 22] use a UK family expenditure survey for years 1976-1995, though the survey tracks fuel expenditure rather than distance traveled per year. There has neither been an estimate of the rebound effect, nor of the effects of fuel prices on mileage, in Great Britain using micro-data. Additionally, there is yet to be a study of how these may differ across different British drivers or geographically.

\subsection{The MOT dataset}

This paper uses data from annual vehicle roadworthiness tests, known as MOT tests in the UK, between years 2006-2017 23] from over 50 million individual vehicles. This dataset has not yet been used for longitudinal analysis to estimate changes in vehicle mileage over time. Past work using this data focused on cross-section analysis between different areas in Great Britain for the year 2011. This showed, for example, that British vehicle ownership and mileage is lower in urban centres than in rural areas 24, 25. The use of geographic information in the MOT data also permitted studies into socio-economic differences in vehicle mileage. Chatterton et al. [26] study the financial implications of vehicle ownership by quantifying annual vehicle tax and fuel expenditure by income groups and geographical areas. This work was complemented by Mattioli et al. 27] who developed an index describing the financial vulnerability of drivers to further price increases. The present study adds to this work by quantifying how drivers react to fuel price changes over time and thus how quickly different drivers may be able to adjust to changes in travel costs.

To summarise, there are few studies to date investigating the rebound effect using micro-level data, and none have analysed driving patterns in Great Britain. This paper quantifies the rebound effect by estimating the response to changes in fuel price, with the side benefit of estimating how drivers might react to changes in fuel taxation. We use the detail of the MOT dataset to investigate differences in responsiveness to fuel price changes between vehicles of different size, fuel efficiency and geographical location. This aids the comparison between literature estimates and helps to better evaluate the effects of efficiency improvements and fuel taxation policies.

\section{Method}

This section begins with a discussion of the model specification and independent variables chosen for this investigation. Section 3.2 then presents the details of the MOT data and other data sources used in this study.

\subsection{Model specification}

This paper makes use of vehicle roadworthiness testing data which includes odometer readings at the time of testing. The miles traveled $(S)$ by vehicle $i$ in each driving period $t$ is calculated as the change in odometer readings between test dates divided by the time between tests. This is modeled as a function of the average price of fuel in Great Britain ( Price $_{t}$ ), national gross domestic product $\left(\mathrm{GDP}_{t}\right)$ and vehicle age $\left(A_{i t}\right)$. To capture seasonal effects, we control for the average rainfall in each postcode $\left(R_{i t}\right)$ and heating degree months $\left(\mathrm{HDM}_{i t}\right)$, a measure of how cold the weather is over the time period in each postcode (explained further in SI). Dummy variables are used to control for the month of each test $\left(M_{i t}\right)$ as well as the time between tests $\left(\gamma_{i t}\right)$, and are included to account for remaining seasonal effects (for example a driving period covering two Christmas holidays may have lower average mileage), as well as other unobserved heterogeneity (e.g. 
vehicles tested much earlier than the average 52 weeks may have abnormal mileage if they have technical issues requiring premature testing). To capture structural differences and any remaining unobserved heterogeneity, we include vehicle fixed effects $\left(\theta_{i}\right)$, which is equivalent to using a dummy variable for each vehicle and captures the average mileage of each individual vehicle. This results in the following logarithmic form:

$$
\ln \left(S_{i t}\right)=\beta X+\epsilon_{i t}
$$

where $X$ is a vector of variables:

$$
\begin{aligned}
X= & {\left[\ln \left(\text { Price }_{t}\right), \ln \left(\mathrm{GDP}_{t}\right), \ln \left(\mathrm{HDM}_{i t}\right),\right.} \\
& \left.\ln \left(R_{i t}\right), A_{i t}, M_{i t}, \gamma_{i t}, \theta_{i}\right]
\end{aligned}
$$

$\beta$ is a vector of the coefficients for each variable and $\epsilon_{i t}$ is an idiosyncratic error term with zero mean. The elasticity of fuel price on mileage $\left(\beta_{\text {Price }}\right)$ is our primary interest as it is equal to $\eta_{P_{E}}(S)$.

The vehicle fixed effects $\left(\theta_{i}\right)$ capture any time-invariant differences between vehicles meaning variables that do not change over time cannot be used as regressors. Any effects associated with the type of vehicle, rated fuel consumption and location of each vehicle are therefore absorbed into the fixed effects. The effects of these variables can be investigated separately by running regressions on subsets of the data or by using dummy variable interaction.

Since vehicle fixed effects are used, the coefficients shown in equation 6 are 'within' estimates (measured at the individual vehicle level) and represent the change in mileage from a temporal change in the explanatory variables rather than 'between' estimates which would measure cross-sectional differences in the data. These elasticities could differ from household elasticities due to substitution effects if multiple vehicle households use a more efficient car in times of high oil price. We investigate whether these substitution effects may occur by considering heterogeneity by vehicle type.

The interest of this paper is the effect that an exogenous change in fuel prices may have on the mileage of vehicles. However, there is a possibility that short term increases in the mileage of British vehicles may have an effect on the price of fuel at the pump. If this were true, then the fuel price would not be exogenous and the effects of demand changes on prices would have to be accounted for. The price of fuel at the pump in the UK is comprised of the underlying price of oil on the international market, an additional government duty and a value added tax (VAT). The international price of fuel is unlikely to be affected by short term fluctuations in the mileage of a small country such as the UK. Similarly, fuel price duty and VAT have remained relatively constant over the period of investigation, though it is possible these may have changed in response to changes in travel demand. To ensure that this is not the case, the Europe Brent spot price is used in a model run as an instrumental variable. This removes the possible effects of government fuel duties and VAT changes. Finally, our model specification estimates an average response to fuel price changes and does not account for any differences in fuel price increases versus decreases.

Many studies distinguish between short-run and longrun elasticities. The former is a change in the order of one year and doesn't account for changes in the stock. Long-run effects are calculated over larger time periods, typically using dynamic models, and therefore account for longer-term social and behavioural changes from changes in travel costs. Estimates of the long-run rebound effect are generally larger than short-run effects [2. A review by Dimitropoulos et al. 3] suggests rebound effects in transport are around 0.12 in the short-run and 0.32 in the long-run, though the majority of studies covered use aggregate data. There are also distinctions between 'direct' and 'indirect' rebound effects [28, 29]. The latter looks into how financial savings from efficiency improvements in one service may be spent on other services and goods which have an energy impact, though there is a limited consensus of the magnitude of these effects 30. Given the relatively short time series and data constraints used in this study, we choose to focus on short-term, 'direct' rebound effects. Finally, we focus on rebound effects on vehicle miles traveled (VMT) rather than passenger miles traveled [31].

\subsection{Data}

In the United Kingdom, all vehicles over 3 years old undergo mandatory annual roadworthiness tests known as MOT tests. From 2005 onwards, the Department for Transport moved to storing the MOT results on a digital system. These results were released in the public domain and the latest 2019 release [23] covers years 2005-2017, though the 2005 year was incomplete meaning the year 2006 is chosen as the start year of the data. In total, there are 275,866,597 test entries in the dataset for 50,155,603 unique cars who passed MOT tests.

Information on vehicle registration plates of each vehicle is removed by the Department for Transport to ensure the data remains anonymous. Instead, each vehicle is given a unique vehicle_id number. Other fields of interest include the vehicle manufacturer and model, engine capacity, fuel type, date of first registration and the odometer reading at each test date. This final entry can be used with the vehicle_id to track the mileage of each vehicle between tests. Each observation in the dataset therefore consists of a driving period between two MOT tests (e.g. 04/01/2007 - 05/02/2008) for each individual vehicle (e.g. vehicle_id=789, Volkswagen Golf 2004 turbo $1200 \mathrm{cc}$ Diesel) and the mileage driven (the difference between odometer readings). The data is cleaned to remove erroneous entries (such as removing entries where the mileage rate exceeds 100,000 miles/year or is negative) as performed by past studies 32. A full list of cleaning procedures is included in the SI.

The publicly available MOT data also includes the general postcode area of the garage performing the test. It is 

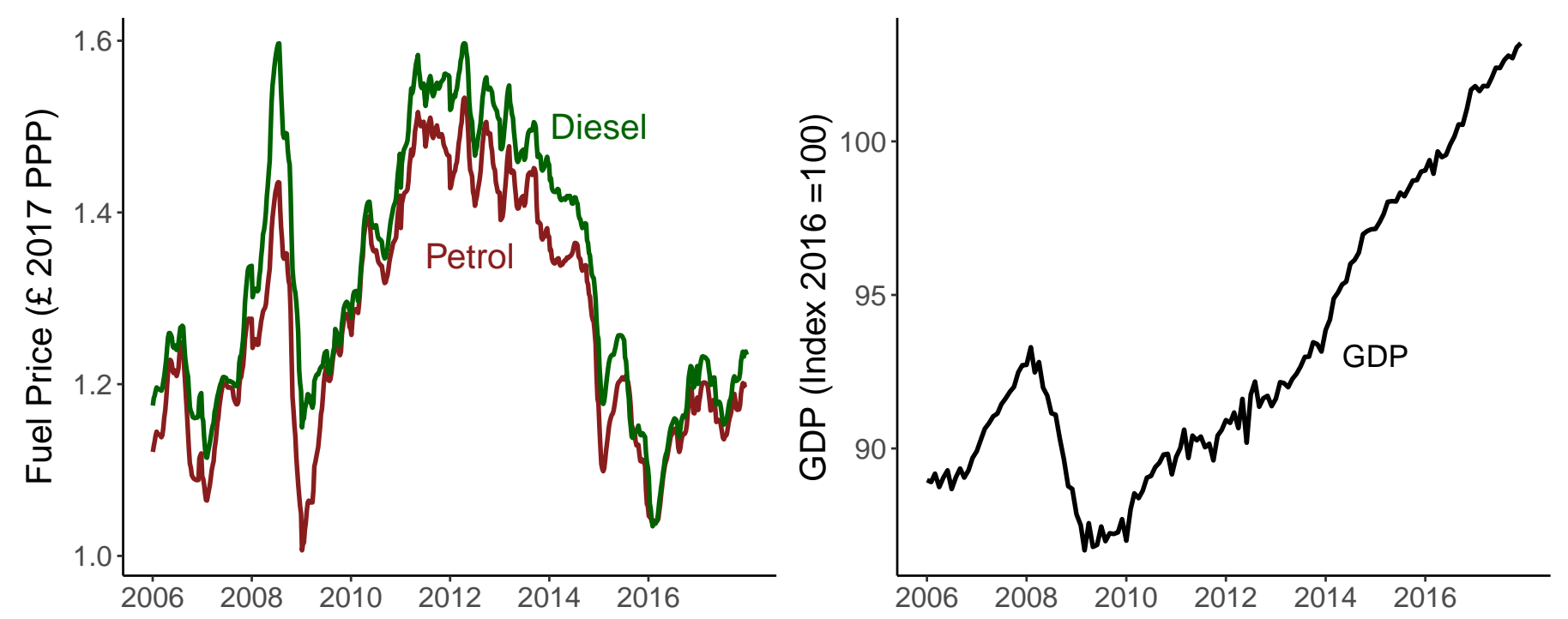

Figure 1: Left=Price of petrol (gasoline) and diesel fuel at pump (including government fuel taxes) and converted to $2017 £$ PPP. Right=UK National Gross Domestic Product (indexed to 2016 levels).


Figure 2: Left=Histogram of vehicle mileage in MOT data (grey) and frequency plots of petrol (red) and diesel vehicles (green). Right=Heating degree months and monthly average precipitation across Great Britain ( $\mathrm{mm})$.

reasonable to assume that drivers test their vehicles close to home, and for the majority of tests, the garage and location of residence fall within the same relatively large postcode area. This approach was also taken by past studies using the MOT data 24. In the absence of data on the socio-economic characteristics of the drivers in the data, the average characteristics of the postcode can be used as a rough proxy for the general social and geographical context of the vehicle.

Weekly fuel price data is sourced from UK BEIS 33. (fig. 1. left) and Europe Brent spot price data is sourced from the US Energy Information Administration [34. Both are corrected to pounds Sterling and 2017 purchasing price parity using OECD consumer price indices 35. Due to data availability, we use the average UK fuel price rather than any more detailed geospatial differences. Monthly, seasonally adjusted GDP data for the UK is sourced from the ONS 36] and shown in figure 1 (right).

Monthly weather data (average temperatures and rainfall) for 2006-2017 is sourced from the UK Centre for Environmental Data Analysis (CEDA) 37] as a $12 \mathrm{~km}$ resolution raster and then aggregated to postcode level using shapefiles 38. Postcode temperature data is used to calculate heating degree months for each postcode (HDM, explained further in SI). The national average HDM and rain are shown in figure 2 (right). Fuel price, GDP and weather variables are averaged at monthly level and associated with the driving period of each vehicle. Median 
income data for the year 2011 is sourced from Experian 39 and aggregated to postcode level. A consistent time series of income by postcode for the period studied is unfortunately not available.

Figure 2 (left) shows a histogram of the annual mileage of the vehicles in the dataset. This resembles a shifted gamma distribution 32 with a long tail where a minority of vehicles have particularly high mileages. Diesel vehicles have, on average, higher mileages than Petrol vehicles.

A previous paper by the authors [40] built a dataset of vehicles sold between 2001 and 2018 using a combination of publicly available data sources [41 43. Using this data, we attribute a size segment (e.g. Small Sedan, SUV) to $91 \%$ of vehicles in the MOT data based on the vehicle manufacturer (e.g. BMW) and generic model (e.g. 3 series). Some vehicles in the MOT data could not be assigned a size segment because they are either old with model names that were no longer sold after the year 2000 (e.g. Jaguar E-Type), or have erroneous name entries.

The dataset created in 40 sourced driver reported, realworld fuel consumption records for new British vehicles sold between 2001 and 2018 and was able to determine a sales-weighted estimate of new car, real-world fuel consumption for the first time. This showed that the difference between manufacturer reported (type-approval) fuel consumption and driver reported (real-world) fuel consumption has been increasing over time. This meant that vehicles sold in later years had a real-world fuel consumption that was on average over $30 \%$ worse than the typeapproval value. Failure to account for this fact could bias investigations into the rebound effects of different types of vehicle. For vehicles registered after the year 2000, we attempt to match a 'real-world' fuel consumption estimate using fuzzy matching algorithms (see [40]) by vehicle manufacturer, model, engine size, fuel type and year of first registration. Since no data on transmission type (Manual/Auto) or drivetrain (AWD) are available in the MOT data, the sales-weighted average data for each group of matched vehicles is used. We are able to match a realworld fuel consumption estimate to $82 \%$ of vehicles registered after the year 2000 .

\begin{tabular}{l|rrrr}
\hline & Mean & Std. & Min. & Max. \\
\hline Annual VMT & 7,421 & 5,807 & 400 & 99,998 \\
Age (years) & 7.94 & 3.55 & 3 & 19 \\
Fuel Price $(£ 2017)$ & 1.30 & 0.13 & 1.01 & 1.56 \\
GDP (£ 2016) $\times 10^{9}$ & 1,821 & 52.6 & 1,735 & 1,937 \\
HDM in Pcd. & 5.37 & 1.09 & 1.38 & 16.1 \\
Rain in Pcd. $(m m)$ & 72.1 & 26.8 & 14.3 & 379 \\
Pcd. Population $\times 10^{3}$ & 676.1 & 356.2 & 2.2 & $2,045.1$
\end{tabular}

Table 2: Summary statistics of main variables from 23,016,519 observations. Pcd.=Postcode

Summary statistics of the data are presented in table 2 and for three example driving periods in table 3. This shows the shares of vehicles in each size segment in the data have remained broadly constant over time with a slight shift to larger SUVs. On average, vehicles on the road have become older and are driven fewer miles every year.

\begin{tabular}{l|rrr}
\hline & $2006 / 7$ & $2011 / 12$ & $2016 / 17$ \\
\hline City \% & 31.4 & 30.7 & 32.5 \\
Medium \% & 28.4 & 25.6 & 25.3 \\
Small Sedan \% & 14.4 & 17.1 & 16.4 \\
Small SUV \% & 0.6 & 0.6 & 1.6 \\
Large Sedan \% & 13.8 & 11.3 & 9.6 \\
SUV/MPV \% & 11.1 & 14.4 & 14.4 \\
Sports \% & 0.2 & 0.3 & 0.3 \\
Tested L/100km* & 7.16 & 6.89 & 6.33 \\
Real world L/100km* & 7.38 & 7.32 & 7.15 \\
Age (Years) & 7.68 & 8.34 & 9.39 \\
Mileage & 7556 & 7297 & 6971
\end{tabular}

Table 3: Summary statistics of three test periods showing share of vehicles by size segment, average vehicle age and annual mileage as well as average Type-approval (Tested) and 'Real-world' fuel consumption expressed in litres of gasoline equivalent per $100 \mathrm{~km}$. *note only vehicles registered after the year 2000 could be attributed fuel consumption estimates.

The average mileage of a group of vehicles between two test years can be determined simply by dividing the sum of the mileages of each vehicle by the number of vehicles. However, this approach has flaws as explained by Wilson et al. 32. The average mileage of all vehicles tested between 2006 and 2007 for example will include some vehicles tested in January 2006 and January 2007 as well as vehicles tested between December 2006 and December 2007. This means the driving period covered in the averaging process covers almost 2 years of driving (Jan 2006 - Dec 2007). This results in locally time averaged data effectively smoothing out short term perturbations which may be of interest. This averaging process can be useful to show general crosssectional differences in mileage between geographic areas and types of vehicles but is inappropriate for estimating short term responses to fuel price changes. For this reason a panel data approach is necessary. The full MOT dataset comprises 275,866,597 rows of data. For computational reasons we take two large samples of the data:

The first sample is used purely for the descriptive results presented in section 4.1. This consists of a random sample of 3 million cars from each year of test data 2006-2016. These are matched with their respective entries in the subsequent test year to create sets of observations of driving periods. This sample is averaged between test years (e.g. 2006 to 2007) to give an important overview of driving trends in Great Britain and the cross-sectional differences between types of vehicles. However, the trends suffer from the smoothing effect (outlined above) and are therefore only appropriate for comparing cross-sectional differences between vehicles and not for analysing responses to fuel price changes.

To estimate fuel price changes using panel methods with fixed effects, individual vehicles need to be tracked over 
time. The data used in the regressions in section 4.2 is created by taking a random sample of 10 million unique vehicle_ids from the full dataset across all years. These 10 million cars are then tracked through time to obtain all driving periods available for this sample of vehicles. After data cleaning and matching procedures this leaves a total of 23,016,519 observations with an average of 3.8 observations for each vehicle_id.

\section{Results}

In this section we present an overview of driving trends in Great Britain from the MOT data. The differences in mileage between size segments and age groups gives greater context to the regression model results presented in section 4.2 which investigates how drivers reacted to changes in fuel prices between 2006 and 2017.

\subsection{Overview of driving trends in Great Britain}

Figure 3 shows how the average annual mileage of vehicles varies by size segment. Larger size segments tend to have higher mileage than smaller vehicles, they also have a higher share of diesel engines explaining the differences in figure 2 (left). For most segments, vehicles are used less intensively over time. This is likely due to increasing vehicle age over the time period (table 2) and a $10 \%$ increase in national vehicles per household 44. The 'small SUV' segment of 'crossover' type vehicles became more popular over time, taking market share from Medium cars in particular. This increase in popularity was also associated with a change in the use of this type of vehicle. New small SUVs sold after 2013 are driven more on average than the fewer older models that once made up this size segment. Figure 4 shows that the average mileage

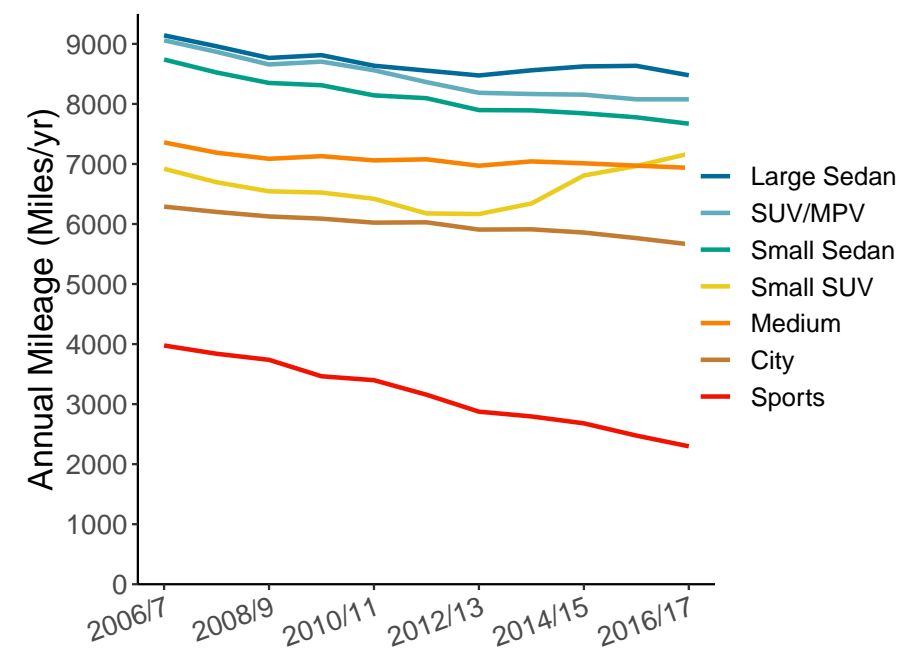

Figure 3: Average annual mileage by size segment.

of vehicles drops with age across all vintages. For every year a car ages, it's average annual mileage drops by approximately 330 miles per year. Similar findings have been shown using national travel survey data by 45. Importantly, these graphs show average mileage per year between two test years and are therefore subject to the smoothing effect detailed in section 3.2 . This means short term fluctuations in mileage due to fuel price changes are averaged out.

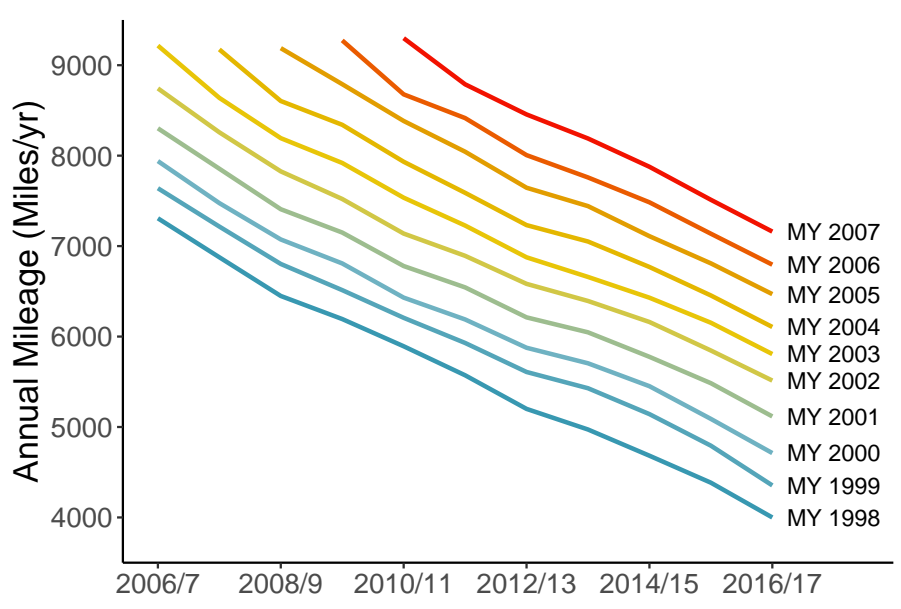

Figure 4: Average annual mileage by model year.

\subsection{Fuel price elasticities of vehicle mileage}

Regression results are presented in table 4 for four different regression models. In the first model (1) Base, the effects of fuel price, GDP and vehicle age on mileage are estimated. The sensitivity of these effects to the addition of controls is then investigated. The second model (2) adds controls for the month of each MOT test and the length of the driving period between tests for each vehicle. These controls are performed by means of dummy variables. The third model (3) additionally controls for weather effects in each postcode using heating degree months (HDM) and total rainfall. Cold weather (increasing HDMs) has a small negative coefficient suggesting vehicle mileage is lower during cold periods. A period with increased rain has a small positive effect on mileage. This effect may be larger with data at a higher degree of temporal resolution. The low $\mathrm{R}^{2}$ values highlight the difficulty in predicting changes in the mileage of individual vehicles with such noisy data. There are an innumerable number of factors that could affect the mileage of individual drivers year-on-year that are not possible to explain with the given data (or perhaps any data). We also note that when using data with such a large number of observations it becomes increasingly possible to obtain statistically significant results $(\mathrm{p}<0.05)$ on variables of interest [46, 47. For this reason we place particular emphasis upon checking that the findings remain robust to the addition/removal of different variables and subsetting data. The appendices detail further investigations including controls for the effects of population growth and removing the effects of GDP. Over all the model formulations, the coefficients of the main variables remain 


\begin{tabular}{l|rrrr}
\hline Parameter & $(1)$ Base & $(2)$ Time Effects & $(3)$ Weather Effects & $(4)$ IV 2SLS \\
\hline lnPrice & $-0.045(0.002)^{* * *}$ & $-0.048(0.002)^{* * *}$ & $-0.046(0.002)^{* * *}$ & $-0.04(0.001)^{* * *}$ \\
lnGDP & $0.12(0.006)^{* * *}$ & $0.15(0.006)^{* * *}$ & $0.089(0.006)^{* * *}$ & $0.15(0.007)^{* * *}$ \\
Age & $-0.035(1 \mathrm{e}-04)^{* * *}$ & $-0.035(1 \mathrm{e}-04)^{* * *}$ & $-0.035(1 \mathrm{e}-04)^{* * *}$ & $-0.036(1 \mathrm{e}-04)^{* * *}$ \\
lnHDM & & & $-0.021(0.001)^{* * *}$ & $-0.018(0.001)^{* * *}$ \\
lnRain & & & $0.004(7 \mathrm{e}-04)^{* * *}$ & $0.004(7 \mathrm{e}-04)^{* * *}$ \\
Month Effects & & $\mathrm{X}$ & $\mathrm{X}$ \\
Period Effects & & $\mathrm{X}$ & $\mathrm{X}$ & $\mathrm{X}$ \\
Vehicle Effects & $\mathrm{X}$ & $\mathrm{X}$ & $\mathrm{X}$ & $\mathrm{X}$ \\
\hline Observations & $23,016,519$ & $23,016,519$ & $23,016,519$ & $23,016,519$ \\
$\mathrm{R}^{2}$ & 0.03 & 0.03 & 0.03 & 0.03
\end{tabular}

Table 4: Regression results for various model formulations. Dependent variable is the natural logarithm of vehicle mileage. Standard errors in parentheses. $\mathrm{X}$ indicates effects are included in a model. Statistical significance: ${ }^{*} \mathrm{p}<0.05,{ }^{* *} \mathrm{p}<0.01,{ }^{* * *} \mathrm{p}<0.001$

relatively constant suggesting the results are robust. Our preferred model specification is Model (3).

To ensure that the UK fuel price is an exogenous variable (independent of vehicle mileage in the UK) the Europe Brent spot price is used as an instrumental variable using 2 stage least-squares regression (2SLS). Model (4) in table 4 shows $\beta_{\text {Price }}$ and other coefficients are similar to the results of previous model specifications, thereby confirming that changes in British vehicle mileage are unlikely to influence British fuel prices or government fuel duties. The first stage results are presented in the SI.

The average response to fuel prices across all vehicles in the dataset is $\eta_{P_{E}}(S) \approx-0.046$. This is lower than the estimate of $\eta_{P_{E}}(S)=-0.152$ reported by Stapleton et al. 12] using British aggregate data for years 1970-2011. We believe there are two likely reasons for this difference. Firstly, the later period of study investigated in this paper likely entails a greater degree of satiation for driving and consequently a lower elasticity (as seen in the USA [21]). Secondly, our elasticity reflects changes on an annual level (a short-run effect), the estimates of Stapleton et al. 12. are a long-run effect. Our estimate is similarly smaller than that found by Gillingham et al. $[18$ of $\approx-0.3$ for Denmark which may again be due to their estimate using data on driving periods over 2-4 years.

Following equation 4. our short-run estimate of $\eta_{P_{E}}(S)=-0.046$ is likely to be similar in magnitude to the short-run rebound effect $\eta_{\varepsilon}(S)$. Our elasticities of GDP (which can be considered to be a measure of income) on vehicle mileage are in the range 0.089-0.15. Goodwin et al. 11] report an average income effect on per vehicle VMT of 0.06 from studies using static models. Stapleton et al. 12 report an average long-run estimate of 0.51 . Whilst our estimates lie within this range, we are cautious to place too much significance upon them as firstly, we use national average GDP data, which is only a rough measure of real income data and secondly, GDP had relatively low variance over the short time period studied.

Although the average response to fuel prices is small, this may differ between drivers based on their type of vehicle or socio-economic circumstances. To investigate possible heterogeneity in $\beta_{\text {Price }}$ by vehicle type and geographical region, regressions are run with dummy variable interactions on fuel price in the following sections.

\subsection{Heterogeneity by vehicle size segment}

\begin{tabular}{l|r}
\hline Parameter & Coefficient \\
\hline lnPrice: City & $0.11(0.003)^{* * *}$ \\
lnPrice: Medium & $-0.038(0.003)^{* * *}$ \\
lnPrice: Small SUV & $-0.077(0.02)^{* * *}$ \\
lnPrice: Small Sedan & $-0.12(0.004)^{* * *}$ \\
lnPrice: SUV/MPV & $-0.19(0.004)^{* * *}$ \\
lnPrice: Large Sedan & $-0.22(0.005)^{* * *}$ \\
lnPrice: Sports & $-0.7(0.04)^{* * *}$ \\
lnGDP & $0.081(0.007)^{* * *}$ \\
Age & $-0.033(1 \mathrm{e}-04)^{* * *}$ \\
lnHDM & $-0.021(0.001)^{* * *}$ \\
lnRain & $0.0042(7 \mathrm{e}-04)^{* * * *}$ \\
Month Effects & $\mathrm{X}$ \\
Period Effects & $\mathrm{X}$ \\
Vehicle Effects & $\mathrm{X}$ \\
\hline Observations & $20,873,256$ \\
$\mathrm{R}^{2}$ & 0.03
\end{tabular}

Table 5: Regression results for by vehicle fuel type and size segment. Dependent variable is the natural logarithm of vehicle miles traveled. Standard errors in parentheses. Statistical significance: ${ }^{*} \mathrm{p}<0.05,{ }^{* *}$ $\mathrm{p}<0.01,{ }^{* * *} \mathrm{p}<0.001$

In table 5 and figure 5 , the sensitivity of different vehicle size segments to fuel price $\left(\beta_{\text {Price }}\right)$ is presented using dummy variable interactions. The results show the responsiveness to fuel price increases for larger vehicle size segments and sports cars. These findings are robust to alternative specifications including subsetting the data based on size segment. Only $91 \%$ of vehicles in the data could be attributed a size segment, meaning the number of observations is less than those used in table 4 Interestingly, the fuel price elasticity of City cars (the smallest vehicle segment) is positive implying they are driven more when fuel prices increase. This may be due to drivers switching between multiple vehicles they own and choosing the more efficient, cheaper vehicle when prices are 
high. We are unable to test this hypothesis explicitly as there is no information in the dataset about the number of vehicles owned by each driver. However, Knittel \& Sandler 14 found that drivers in California with a more efficient vehicle in their household appear more responsive to changes in fuel price than those without, suggesting that vehicle switching does occur. If this were true in Great Britain it would suggest the assumption of the rebound effect being equal in magnitude to the price elasticity is flawed, a point we discuss in greater depth in section 4.6 .

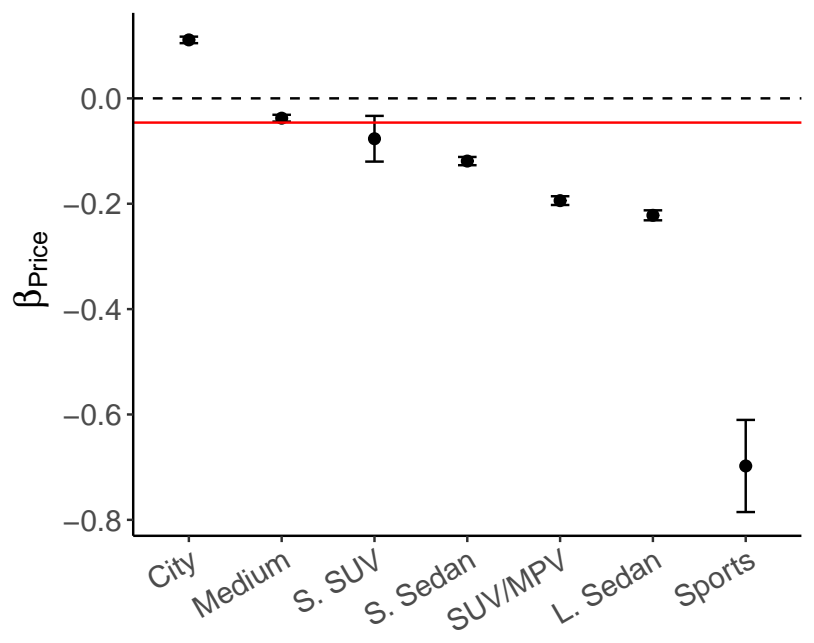

Figure 5: Heterogeneity of the price elasticity of vehicle mileage by vehicle size segment with $\pm 1.96 \times \mathrm{SE}$ confidence intervals. The red line is the average $\beta_{\text {Price }}$ from model (3) in table 4

The results show that increasing fuel taxation may have a greater effect at reducing mileage of larger vehicles than that of smaller vehicles, leading to energy savings. However, it is not clear from the outset whether these findings are due to (i) larger vehicles being less fuel efficient, (ii) larger vehicles being driven a higher annual mileage than other size segments (seen in fig. 3), or (iii) the owners of large vehicles being more likely to also own a small vehicle to use in times of high oil price. The larger vehicles in the data are less fuel efficient on a per mile basis and travel a higher annual mileage (Sports cars are the exception to this rule since they have a high fuel consumption but a low annual mileage). Whilst we are unable to investigate (iii) further, the importance of mileage and fuel consumption on $\beta_{\text {Price }}$ is investigated in section 4.4 .

\subsection{Heterogeneity by vehicle fuel efficiency}

This section investigates how the response to fuel price changes may change for vehicles of different fuel consumption $(\mathrm{L} / 100 \mathrm{~km})$. Table 6 reports regression results from interacting the fuel price with a 'real-world' fuel consumption range. The $\beta_{\text {Price }}$ elasticities for each fuel consumption range are plotted graphically in figure 6 . These findings show $\beta_{\text {Price }}$ increases in magnitude for higher fuel consumption vehicles suggesting they are the most responsive to fuel price.
Data on the real world fuel consumption of cars is only available for cars sold after the year 2000, which reduces the number of cars in the sample. However, this is unlikely to bias the estimates (see table A7 in SI) given we already control for the age of the car and include vehicle fixed effects.

To determine the effect that average annual mileage may have, Figure 6 (right) shows the average mileage of vehicles in each fuel consumption range for three different driving periods. This shows that the annual mileage of vehicles in each range of fuel consumption is broadly similar and suggests that the differences in $\beta_{\text {Price }}$ shown in Figure 6 (left) are predominantly due to differences in fuel consumption rather than mileage rates.

The most efficient vehicles $(5.0-5.5 \mathrm{~L} / 100 \mathrm{~km})$ are also more responsive than average. However, we are cautious to attribute particular significance to this finding; in the early years of 2006/7 this bin had relatively high mileage (fig 6. right) suggesting the usage and types of these vehicles in this group has changed over the time period studied. This is not the case for other bins of vehicle efficiency. These findings complement those presented in section 4.3 and suggest that drivers of larger vehicles appear more responsive to changes in fuel prices due to worse fuel efficiency.

\begin{tabular}{l|r}
\hline Parameter & Coefficient \\
\hline lnPrice: $5-5.5 \mathrm{~L} / 100 \mathrm{~km}$ & $-0.12(0.01)^{* * *}$ \\
lnPrice: $5.5-6 \mathrm{~L} / 100 \mathrm{~km}$ & $0.024(0.008)^{* *}$ \\
lnPrice: $6-6.5 \mathrm{~L} / 100 \mathrm{~km}$ & $0.021(0.005)^{* * *}$ \\
lnPrice: $6.5-7 \mathrm{~L} / 100 \mathrm{~km}$ & $-0.045(0.005)^{* * *}$ \\
lnPrice: $7-7.5 \mathrm{~L} / 100 \mathrm{~km}$ & $-0.04(0.005)^{* * *}$ \\
lnPrice: $7.5-8 \mathrm{~L} / 100 \mathrm{~km}$ & $-0.1(0.005)^{* * *}$ \\
lnPrice: $8-8.5 \mathrm{~L} / 100 \mathrm{~km}$ & $-0.1(0.008)^{* * *}$ \\
lnPrice: $8.5-9 \mathrm{~L} / 100 \mathrm{~km}$ & $-0.15(0.01)^{* * *}$ \\
lnPrice: $9-9.5 \mathrm{~L} / 100 \mathrm{~km}$ & $-0.19(0.02)^{* * *}$ \\
lnGDP & $0.14(0.009)^{* * *}$ \\
Age & $-0.034(1 \mathrm{e}-04)^{* * *}$ \\
lnHDM & $-0.021(0.001)^{* * *}$ \\
lnRain & $0.006(9 \mathrm{e}-04)^{* * *}$ \\
Month Effects & $\mathrm{X}$ \\
Period Effects & $\mathrm{X}$ \\
Vehicle Effects & $\mathrm{X}$ \\
\hline Observations & 0.03 \\
$\mathrm{R}^{2}$ & 12200570 \\
\end{tabular}

Table 6: Regression results by real world fuel consumption of vehicles. Dependent variable is the natural logarithm of vehicle miles traveled. Fuel consumption in litres of gasoline equivalent. Standard errors in parentheses. Statistical significance: ${ }^{*} \mathrm{p}<0.05,{ }^{* *} \mathrm{p}<0.01$, $* * * \mathrm{p}<0.001$

\subsection{Heterogeneity by income and population density of postcode}

It is possible that the rebound effect/fuel price elasticity may differ based on levels of income, annual mileage or other geographical and social factors. We investigate this by interacting the fuel price with each of the 118 postcodes 

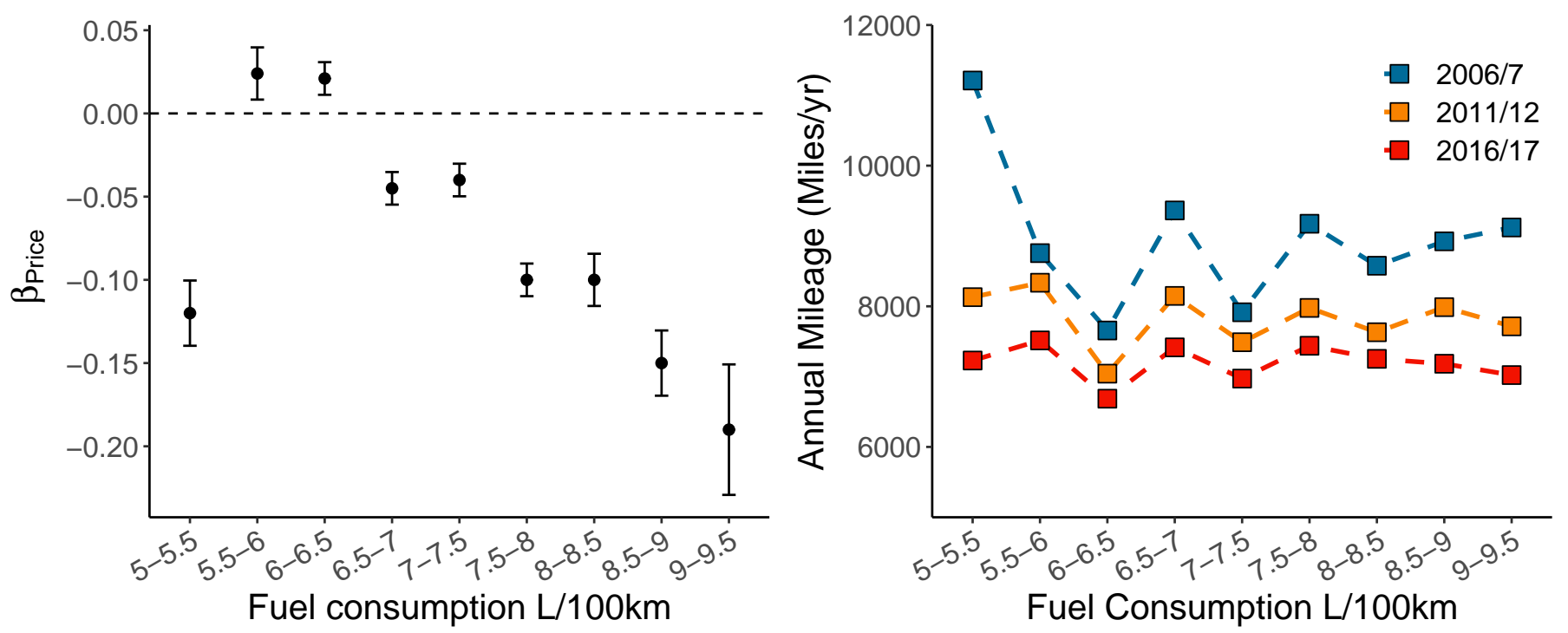

Figure 6: Heterogeneity of the price elasticity of vehicle mileage by real world fuel consumption group with $\pm 1.96 \times$ SE confidence intervals.

in the data. To aid the interpretation of these results, figure 7 shows a map in which the colour of the postcode is proportional to the magnitude of $\beta_{\text {Price. }}$ We also present scatter plots (right) where the estimated $\beta_{\text {Price }}$ for each postcode is plotted against the average vehicle mileage, income and population density of each postcode in year 2011. Only statistically significant results are plotted (all others are dark grey, no data is available for Northern Ireland since the MOT dataset covers only Great Britain).

The responsiveness to fuel price changes is loosely related to the average income in each postcode (fig. 7, right), while stronger relationships are found between the average annual mileage of vehicles and the population density in each postcode. These scatter plots would suggest drivers living in more urban areas with lower annual vehicle mileage are more responsive to fuel price changes. It is possible this is due to a greater availability of public transport modes. A driver with high annual mileage and living in a more rural postcode may display less responsiveness in fuel price changes if they have no alternative but to drive. It is possible that these trends could be affected by the types of vehicles present in each postcode. However, there is no obvious correlation between the share of large vehicles in each postcode and the responsiveness to fuel price, making any significant bias unlikely (fig. A9). Our results can be compared to the findings of Gillingham et al. [15, 18, who similarly find $\beta_{\text {Price }}$ becomes more negative (i.e. larger magnitude) for drivers in higher income, urban areas in both California and Denmark.

These findings suggest that drivers in some rural, low income areas of Great Britain may be unable to moderate their mileage in response to short term fuel price changes, leading to financial burdens. These insights from the use of the MOT micro-data can therefore be used to aid policy decisions on the social equity effects of fuel taxation and fuel price changes.

\subsection{Limitations and future work}

The model used in this paper could be used in future research to examine the effects of local policy interventions such as congestion charges on vehicle mileage. It might also be used to investigate the effects of changes in public transport provision over time. Doing so would require data at a higher level of geographical detail than the postcode area data provided in the publicly available MOT dataset used in this study (explained further in the SI). One limitation in the data used in this paper is the size of postcodes which are somewhat socially and geographically heterogeneous. The ideal data would have the geographical resolution to better distinguish between urban and rural areas as public transport and environmental policies are predominantly present in urban contexts. The effects of local policies could be investigated using dummy variables on the year of introduction in each city and public transport trips could be introduced as an additional time series continuous variable. More granular geographical resolution may also identify even higher 'hot spots' of price elasticity and may be able to better control for average income and other socio-economic factors.

If public service provision is indeed a factor determining the fuel price elasticity of mileage it would draw into question the convention of assuming rebound effects are of equal magnitude to fuel price elasticities and thus merits further research. Similarly, possible vehicle switching (discussed in section 4.3 would also mean $\eta_{P_{E}}(S)$ may not equal $-\eta_{\varepsilon}(S)$, though would likely still remain a similar order of magnitude at the aggregate level across all vehicles.

Additional considerations cover possible non-linearities in the response to fuel prices. The average fuel price across driving periods changed by a maximum of $\pm 20 \%$ over the time period investigated (see table A3). Changes outside this range may lead to larger elasticities. This could have 

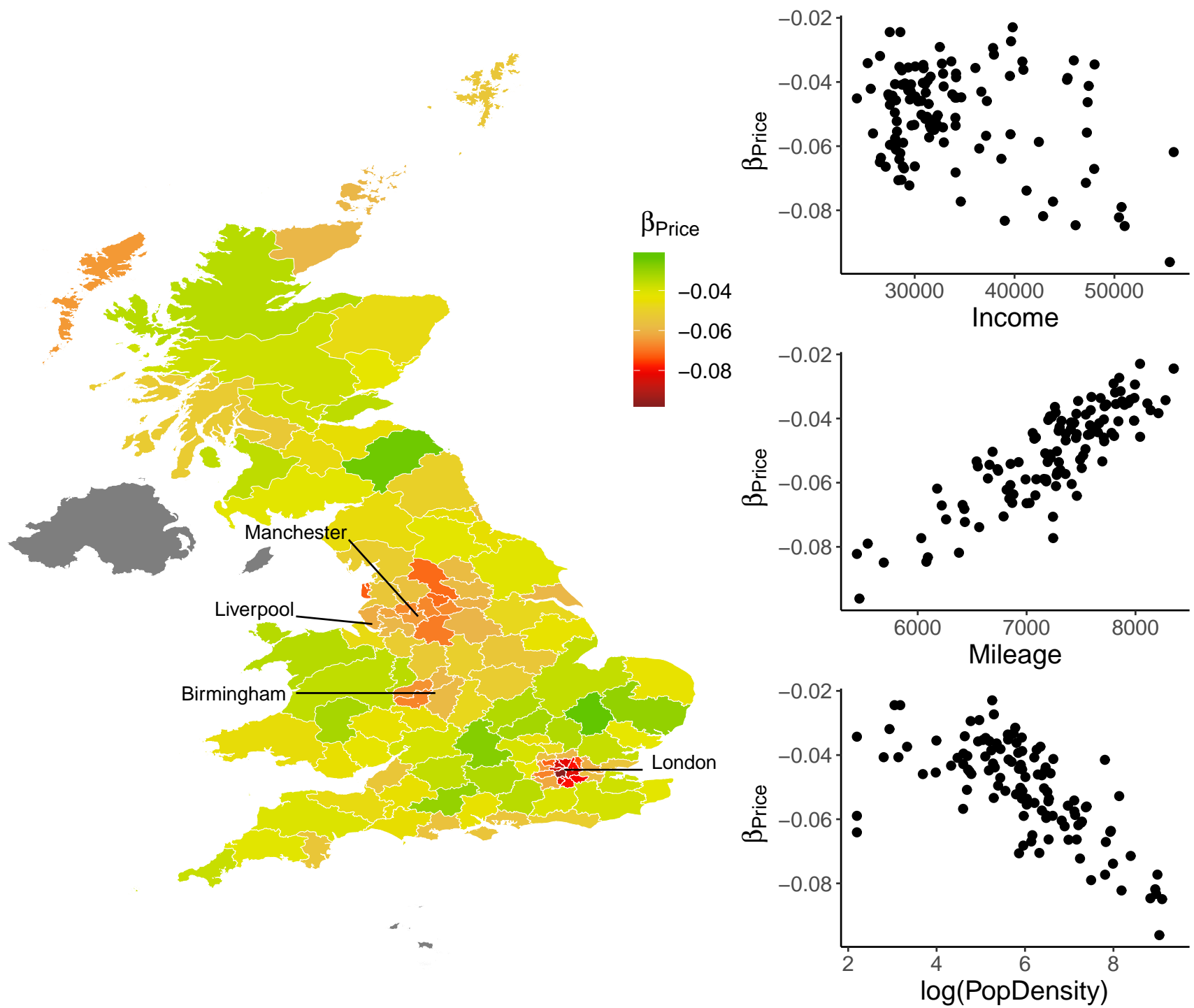

Figure 7: Heterogeneity of the price elasticity of vehicle mileage. Left $=$ map of $\beta_{\text {Price }}$ by postcode. Postcodes where elasticities are not significant at the $\mathrm{p}=0.05$ level are coloured grey. Right $=$ scatters of $\beta_{\text {Price }}$ by postcode vs. average mileage, median income and natural log population density $\mathrm{pp} / \mathrm{km}^{2}$ (2011 levels).

implications for rebound effects as shifting to an electric vehicle can lead to marginal travel cost savings in the order of $50-70 \%$.

\section{Conclusions}

This paper investigates the effect that vehicle efficiency improvements might have on stimulating higher mileage, known as the rebound effect. We estimate the magnitude of this effect in Great Britain between 2006 and 2017 by estimating the response of vehicle mileage to fuel price changes. Our findings show that vehicle efficiency improvements are unlikely to trigger short-term increases in vehicle mileage. This means the rebound effect is likely to be negligibly small and any additional mileage stimulated by efficiency improvements is unlikely to significantly reduce energy savings in the short-term.
We show that the mileage of British drivers' is inelastic to fuel price changes. A $10 \%$ increase in fuel price would lead to a $0.46 \%$ decrease in mileage; for the average vehicle traveling $\approx 7400$ miles per year, this is equivalent to a decrease of just 34 miles. Fuel taxes are therefore unlikely to have an important short-term effect on vehicle mileage.

Whilst these effects are small, we find evidence that drivers of larger and less fuel efficient vehicles are more responsive to fuel price changes than average. Our findings also show drivers in rural areas with relatively high annual mileage are less responsive to fuel price changes than drivers in more populous areas, which are possibly less dependent upon the private vehicle. Since a number of these rural areas have lower than average income, this raises social equity concerns. If car dependent drivers are unable to adjust their mileage in response to changes in fuel price (whether from changes in fuel tax or from mar- 
ket fluctuations) they may have to absorb the additional costs of travel.

\section{Acknowledgements}

This work was funded under EPSRC grant numbers: $\mathrm{EP} / \mathrm{M} 506485 / 1$ and EP/M508007/1.

\section{References}

[1] L. Paoli, J. Cullen, Technical limits for energy conversion efficiency, Energy (2019) 116228

[2] S. Sorrell, J. Dimitropoulos, M. Sommerville, Empirical estimates of the direct rebound effect: A review, Energy Policy 37 (4) (2009) 1356-1371.

[3] A. Dimitropoulos, W. Oueslati, C. Sintek, The Rebound Effect in Road Transport, OECD Environment Working Papers.

[4] N. Chan, K. Gillingham, The Microeconomic Theory of the Rebound Effect: Nuances, Externalities, and Welfare, Journal of the Association of Environmental and Resource Economists 2 (1) (2015) 133-159.

[5] S. Li, C. Timmins, R. H. von Haefen, R. H. V. Haefen, How Do Gasoline Prices Affect Fleet Fuel Economy?, American Economic Journal: Economic Policy 1 (2) (2009) 113-137.

[6] L. Ryan, S. Ferreira, F. Convery, The impact of fiscal and other measures on new passenger car sales and $\mathrm{CO} 2$ emissions intensity: Evidence from Europe, Energy Economics 31 (3) (2009) 365-374.

URL http://dx.doi.org/10.1016/j.eneco.2008.11.011

[7] S. Sorrell, J. Dimitropoulos, The rebound effect: Microeconomic definitions, limitations and extensions, Ecological Economics 65 (3) (2007) 636-649.

[8] K. A. Small, K. V. Dender, Fuel Efficiency and Motor Vehicle Travel: The Declining Rebound Effect, Energy Journal 28 (1) (2007) 25-51.

[9] B. A. M. Bento, L. H. Goulder, M. R. Jacobsen, R. H. V. Haefen, Distributional and Efficiency Impacts of Increased US Gasoline Taxes, American Economic Association 99 (3) (2009) 667-699.

[10] L. A. Greening, D. L. Greene, C. Di, C. Difiglio, Energy efficiency and consumption - the rebound effect - a survey, Energy Policy 28 (6-7) (2000) 389-401.

[11] P. Goodwin, J. Dargay, M. Hanly, Elasticities of road traffic and fuel consumption with respect to price and income: A review, Transport Reviews 24 (3) (2004) 275-292.

[12] L. Stapleton, S. Sorrell, T. Schwanen, Estimating direct rebound effects for personal automotive travel in Great Britain, Energy Economics 54 (2016) 313-325.

URL http://dx.doi.org/10.1016/j.eneco.2015.12.012

[13] M. Frondel, N. Ritter, C. Vance, Heterogeneity in the rebound effect: Further evidence for Germany, Energy Economics 34 (2) (2012) 461-467.

URL http://dx.doi.org/10.1016/j.eneco.2011.10.016

[14] C. Knittel, R. Sandler, The Welfare Impact of Indirect Pigouvian Taxation, NBER working paper series 18849.

[15] K. Gillingham, Identifying the elasticity of driving: Evidence from a gasoline price shock in California, Regional Science and Urban Economics 47 (1) (2014) 13-24. URL http://dx.doi.org/10.1016/j.regsciurbeco.2013.08. 004

[16] A. Langer, V. Maheshri, C. Winston, From gallons to miles: A disaggregate analysis of automobile travel and externality taxes, Journal of Public Economics 152 (2017) 34-46.

[17] K. Gillingham, A. Jenn, I. M. L. Azevedo, Heterogeneity in the response to gasoline prices: Evidence from Pennsylvania and implications for the rebound effect, Energy Economics 52 (2015) S41-S52.

URL http://dx.doi .org/10.1016/j . eneco.2015.08.011
[18] K. Gillingham, A. Munk-Nielsen, A Tale Of two tails: Commuting and the fuel price response in driving, Journal of Urban Economics 109 (September 2018) (2019) 27-40.

[19] K. M. Hymel, K. A. Small, K. V. Dender, Induced demand and rebound effects in road transport, Transportation Research Part B: Methodological 44 (10) (2010) 1220-1241. URL http://dx.doi.org/10.1016/j.trb.2010.02.007

[20] K. M. Hymel, K. A. Small, The rebound effect for automobile travel: Asymmetric response to price changes and novel features of the 2000s, Energy Economics 49 (2015) 93-103. URL http://dx.doi.org/10.1016/j.eneco.2014.12.016

[21] J. E. Hughes, C. R. Knittel, D. Sperling, Evidence of a shift in the short-run price elasticity of gasoline demand, The Energy Journal 29 (1) (2008) 113-134.

[22] J. Dargay, The effect of prices and income on car travel in the UK, Transportation Research Part A: Policy and Practice 41 (10) (2007) 949-960.

[23] UK Driver Vehicle Standards Agency, Anonymised MOT tests and results (2019).

URL anonymised \{\}$\left._{-}\right\}$mot $\left\{\begin{array}{l}\text { _test } \\ \text { t. }\end{array}\right.$

[24] T. Chatterton, J. Barnes, R. E. Wilson, J. Anable, S. Cairns, Use of a novel dataset to explore spatial and social variations in car type, size, usage and emissions, Transportation Research Part D: Transport and Environment 39 (2015) 151-164. URL http://dx.doi.org/10.1016/j.trd.2015.06.003

[25] S. Cairns, J. Anable, T. Chatterton, E. Wilson, C. Morton, MOToring along: The lives of cars seen through licensing and test data, Tech. Rep. November, RAC Foundation (2017). URL http://eprints . uwe.ac.uk/33834/

[26] T. J. Chatterton, J. Anable, J. Barnes, G. Yeboah, Mapping household direct energy consumption in the United Kingdom to provide a new perspective on energy justice, Energy Research \& Social Science 18 (2016) 71-87. URL http://dx.doi.org/10.1016/j.erss.2016.04.013

[27] G. Mattioli, J. Anable, K. Vrotsou, Car dependent practices : Findings from a sequence pattern mining study of UK time use data, Transportation Research Part A 89 (2016) 56-72. URL http://dx.doi.org/10.1016/j.tra.2016.04.010

[28] A. Druckman, M. Chitnis, S. Sorrell, T. Jackson, Missing carbon reductions? Exploring rebound and backfire effects in UK households, Energy Policy 39 (6) (2011) 3572. URL http://dx.doi.org/10.1016/j.enpol.2011.03.058

[29] M. Chitnis, S. Sorrell, A. Druckman, S. K. Firth, T. Jackson, Who rebounds most? Estimating direct and indirect rebound effects for different UK socioeconomic groups, Ecological Economics 106 (2014) 12-32. URL http://dx.doi.org/10.1016/j.ecolecon.2014.07.003

[30] S. Sorrell, B. Gatersleben, A. Druckman, Energy sufficiency and the rebound effects, Concept paper for the European Council for an Energy Efficient Economy.

[31] J. M. Cullen, J. M. Allwood, The efficient use of energy: Tracing the global flow of energy from fuel to service, Energy Policy 38 (1) (2010) 75-81. URL http://dx.doi.org/10.1016/j.enpol.2009.08.054

[32] R. E. Wilson, S. Cairns, S. Notley, J. Anable, T. Chatterton, F. McLeod, Techniques for the inference of mileage rates from MOT data., Transportation Planning \& Technology 36 (1) (2013) 130-143.

[33] BEIS, Weekly Road Fuel Prices (2019).

[34] EIA, Europe Brent Spot Price FOB 1987-2019, U.S. Energy Information Administration.

URL https://www.eia.gov/dnav/pet/hist/LeafHandler. ash $\mathrm{n}$ n=PET $\{\&\}_{\mathrm{s}}=\mathrm{RBRTE}\{\&\}_{\mathrm{f}}=\mathrm{M}$

[35] OECD, Consumer Price Indicies Database (2018). URL https://stats.oecd.org/Index.aspx?DataSetCode= PRICES \{_\}CPI

[36] ONS, Monthly GDP and main sectors to four decimal places (2019).

URL grossdomesticproductgdp/datasets/ 
monthlygdpandmainsectorstof ourdecimalplaces

[37] Met Office, HadUK-Grid Gridded Climate Observations on a $12 \mathrm{~km}$ grid over the UK for 1862-2017. Centre for Environmental Data Analysis (2018).

URL

https://catalogue.ceda.ac.uk/uuid/

2a62652a4fe6412693123dd6328f6dc8

[38] Open Door Logistics, Postcode Shapefiles (2017).

[39] Experian, UK Household Income 2011 by LSOA (2011).

[40] M. Craglia, J. Cullen, Do technical improvements lead to real efficiency gains? Disaggregating changes in transport energy intensity, Energy Policy 134 (April) (2019) 110991.

URL https://linkinghub.elsevier.com/retrieve/pii/ S0301421519305786

[41] D. Harrison, D. Powell, www.honestjohn.co.uk/real-mpg/ (2018).

URL www . honestjohn.co.uk/real-mpg/

[42] T. Fischl, https://www.spritmonitor.de/en/ (2018).

URL https://www.spritmonitor.de/en/

[43] Z. McGregor, www.carfolio.com (2017).

[44] UK Department for Transport, Table NTS9902 Household car ownership by region and Rural-Urban Classification: England (2020).

[45] A. C. Serrenho, J. B. Norman, J. M. Allwood, The impact of reducing car weight on global emissions: the future fleet in Great Britain, Philosophical Transactions of the Royal Society A: Mathematical, Physical and Engineering Sciences.

[46] R. Nuzzo, Statistical errors, Nature 506 (13) (2014) 150-152.

[47] R. J. Smith, The continuing misuse of null hypothesis significance testing in biological anthropology, American Journal of Physical Anthropology 166 (1) (2018) 236-245. 